\title{
Oviposition at low temperatures - late season negatively affects the leaf beetle Galeruca tanaceti (Coleoptera: Galerucinae) but not its specialised egg parasitoid Oomyzus galerucivorus (Hymenoptera: Eulophidae)
}

\author{
Torsten MEINERS ${ }^{1}$, BARBARA RANDLKOFER $^{1,2}$ and ELISABETH OBERMAIER ${ }^{2}$ \\ ${ }^{1}$ Department of Applied Zoology/Animal Ecology, Freie Universität Berlin, Haderslebener Str. 9, D-12163 Berlin, Germany; \\ e-mail: meito@zedat.fu-berlin.de \\ ${ }^{2}$ Field Station of the University of Würzburg, Glashüttenstr. 5, 96181 Rauhenebrach, Germany
}

Key words. Galerucinae, Galeruca tanaceti, Eulophidae, Oomyzus galerucivorus, parasitoid-host interactions, phenology, seasonal activity, temperature dependency, tansy leaf beetle

\begin{abstract}
Insects experience important selection pressures from their parasitoids, which affect both their population dynamics and their evolutionary responses. The interaction between the egg parasitoid Oomyzus galerucivorus Graham (Hymenoptera: Eulophidae) and its chrysomelid host Galeruca tanaceti L. (Coleoptera: Galerucinae) was investigated with the particular aim determining whether the chrysomelid host can escape its parasitoid by ovipositing late in the year as early as September. Although the leaf beetle and its parasitoid emerge in April, G. tanaceti starts to oviposit after spending the summer in reproductive diapause. The objective was to determine, whether the small parasitic wasp can parasitise its host's eggs even at the end of its host's reproductive season in December, when temperatures are low. Beetle oviposition, parasitism rates and temperatures were measured on three comparable mesoxerophytic grassland sites over the coarse of a season. Beetle oviposition, but not parasitism, was significantly positively dependent on temperature. Rate of oviposition decreased over the oviposition period with decrease in temperature. In contrast, after a lag phase of 1-2 weeks at the beginning of the oviposition period in September beetle egg clutches were parasitised at a constant rate until the end of the season in December. Host eggs were parasitised even at mean daily temperatures of $0-6^{\circ} \mathrm{C}$. Thus the tansy leaf beetle does not escape from egg parasitism by ovipositing late in the season in central Germany.
\end{abstract}

\section{INTRODUCTION}

Parasitoid-host interactions are characterised by the hosts' attempts to escape parasitism and the parasitoids' efforts to follow their hosts (e.g., Price et al., 1980). Differences in mortality due to natural enemies in different locations can influence the habitat choice and determine the niches (enemy free space) of herbivorous insects (Berdegue et al., 1996). Effects of predators and parasitoids on the spatial distribution of herbivores have been shown in several instances (Rausher, 1979; Stamp \& Bowers, 1988; Hopkins \& Dixon, 1997). Hosts, however, might gain enemy free space by changing their temporal activity patterns (Price et al., 1980; Jeffreys \& Lawton, 1984; Berdegue et al., 1996), e.g. when they are active under environmental conditions that affect the parasitoids more negatively than themselves. Due to their small size and associated thermoregulatory constraints (Willmer, 1985) egg parasitoids might be more strongly physiologically restricted and experience a higher mortality or might be less active in unfavourable environmental conditions (e.g., at high or low temperatures and in drought conditions) than their much larger hosts. There are only a few studies on the phenology of host-parasitoid interactions and even fewer consider the effect of temperature or evaluate the existence of enemy free space in time for the host (Clancy \& Price, 1987; Strohm et al., 2001).

The phenology of the polyphagous tansy leaf beetle, Galeruca tanaceti (Coleoptera: Chrysomelidae) and its chalcidoid egg parasitoid Oomyzus galerucivorus Graham
(Hymenoptera: Eulophidae) were investigated to determine whether the chrysomelid host gains temporal enemy free space by ovipositing late in the season.

The tansy leaf beetle is univoltine and present all over Europe and in the East Palaearctic region, Near East and North Africa (Fauna Europaea Web Service, 2004; version 1.1, http://www.faunaeur.org). From September to December this beetle deposits eggs, which remain in diapause over winter (Fig. 1) (Prevett, 1953; Siew, 1966). After hatching in April, pupation and eclosion in June, adult beetles remain in a reproductive summer diapause, feeding periodically, although they spend most of the time in the ground despite the fact that food plant quality and quantity during summer are sufficient (Obermaier \& Zwölfer, 1999).

The egg parasitoid O. galerucivorus parasitises several species of Galeruca in Europe (Sinacori \& Mineo, 1993), however, its main host in Germany (and the only host at the study sites) is the tansy leaf beetle. Although the existence of an alternative host cannot be ruled out, it is unlikely that $O$. galerucivorus parasitises eggs of species other than Galeruca, since the extrachorion is unique to Galeruca species (Messner, 1983) and the parasitoid uses chemicals in the extrachorion for host recognition and acceptance (Meiners et al., 1997). G. pomonae, the only possible alternative Galeruca host in the study area shares the same phenology as $G$. tanaceti.

Thus, after hatching in April, it is likely that adult parasitoids have to survive from 5-6 months until Galeruca 
females emerge from reproductive diapause in September, since there are no Galeruca eggs in summer (Fig. 1). It is known from the rearing of $O$. galerucivorus that this parasitoid can survive more than four months in the laboratory on honey water (T. Meiners, pers. observ.). The objective of this study was to determine whether the egg parasitoid can parasitise its host right up to the end of the beetles reproductive season, even when temperatures are low, or whether the chrysomelid gains temporal enemy free space by ovipositing late in the season.

The following questions were asked: (1) Does the rate of parasitism decline during the coarse of the oviposition season? (2) Does temperature affect the number of egg clutches deposited by the tansy leaf beetle? (3) Do low temperatures have a negative impact on parasitoid activity?

\section{MATERIAL AND METHODS}

\section{Study site}

The field study was conducted in the nature conservation area "Hohe Wann" in Lower Franconia, Germany (ca. $10^{\circ} 50^{\prime} \mathrm{N}$, $50^{\circ} 33^{\prime} \mathrm{W}$; about $50 \mathrm{~km}$ south of Bamberg), in the autumn of 2001. It involved three mesoxerophytic grassland sites ranging from $1100-5000 \mathrm{~m}^{2}$ and was partly conducted on subareas (size 1100-2800 $\mathrm{m}^{2}$ ) of all three sites. These three sites were similar in most aspects so that a comparison of the oviposition phenology of the beetle and the parasitoid could be justified. All three sites had sufficiently high densities of ovipositing females, a moderate density ( $1-4 \%$ of the total vegetation cover) of the main host plant yarrow, Achillea millefolium, comparable slopes, the same biotope type (semi-arid grassland), were located at approximately the same altitude (Prappach $300 \mathrm{~m}$, Schafhof $280 \mathrm{~m}$ and Rauchberg $343 \mathrm{~m}$ above $\mathrm{NN}$ ) and were 909-2190 m apart from each other. They differed, however, in their inclination. The site Prappach has a north-west orientation, the sites Schafhof and Rauchberg southerly orientations.

\section{Phenology of oviposition and parasitism}

Starting at the beginning of August all three sites were searched for 3-4 h for egg clutches every four days by slowly walking transects that were placed $1.5 \mathrm{~m}$ apart all over the study site. The vegetation on each side of a given path was searched thoroughly. All egg clutches found on each date were consecutively numbered and marked with coloured tape, so that newly deposited egg clutches could be easily recognised. The tape was applied to the plant stem above the egg clutch or to a neighbouring stem to avoid disturbance of parasitoids walking up the stem.

18 marked egg clutches recorded on each sampling date were randomly (by drawing numbers) sampled 7 days after deposition at each site. It is known that the egg parasitoid will only oviposit in eggs that are less than seven days old (M. Hilker, Freie Universität Berlin, unpubl. data). Towards the end of the oviposition period the number of newly oviposited egg clutches declined below 18 and all egg clutches were sampled.

\section{Culturing of host eggs}

All egg clutches collected from the sites before December were put separately in vials, closed with a very fine PVC gauze and kept outdoors under field conditions in the shade until the end of November to ensure the natural development of larvae and parasitoids. Afterwards they were kept together with the egg clutches that were sampled in December for several weeks in the laboratory at room temperature $\left(\sim 20^{\circ} \mathrm{C}\right)$ and under artificial light (8L : 16D) until larvae and parasitoids hatched. The PVC gauze sealing the vials was sprayed every three days with water to prevent egg clutches from drying out.

\section{Temperature measurement in the field}

At all three sites the temperature was recorded every hour from September until December using a thermobutton datalogger (i-button, Maxim/Dallas). The logger was attached to a stick at a height of about $0.4 \mathrm{~m}$ (mean oviposition height of $G$. tanaceti according to Scherf, 1966), shaded and positioned centrally at each site. For Spearman rank correlations and linear regressions of egg clutch number and rate of parasitism with temperature, temperature means per site were used. The temperature was averaged over the periods of 7 days during which the newly oviposited egg clutches were exposed to parasitism.

\section{Data analysis}

Spearman rank correlations were used to analyse relations between temperature and the population-wide oviposition rates and parasitism at the sites Schafhof, Prappach and Rauchberg (Sokal \& Rohlf, 1994). For these analyses the number of newly deposited egg clutches of $G$. tanaceti on each date as well as the respective parasitism rate were correlated with temperature. Resulting correlation coefficients for the sites were combined using a meta-analysis (Eisend, 2004). In order to elucidate if the egg clutches laid later in the season experienced less parasitism, linear regressions were calculated for each of the three sites with the residuals of the regressions of parasitism on temperature, and of egg clutch numbers on temperature. A residual is the difference between a measured parasitism rate or egg clutch number on a certain date and the sample average. By using the residuals, data were corrected for temperature effects. Prior to analysis, data including percentage values were arc-sintransformed and all data were tested for normal distribution. All procedures were calculated using the software package SPSS 12.0.

\section{RESULTS}

\section{Oviposition of the leaf beetle}

Oviposition started at all three sites in mid-September (Fig. 2A) and the number of egg clutches deposited every 4 days per site increased over the next 3-4 weeks to a peak level (Schafhof 124/ Prappach 56/ Rauchberg 65) and then slowly declined to a low level (5-11 egg clutches) in mid November. When the oviposition activity stopped in the middle of December, 1017 egg clutches had been located at Schafhof, 362 at Prappach, and 475 at Rauchberg, respectively.

\section{Parasitism}

Parasitism started at the three sites 9-12 days after the onset of host oviposition (Fig. 2B). At Schafhof it increased within 13 days from $33 \%$ to $89 \%$ of the egg clutches parasitised and stayed between 70 and $83 \%$ until the beginning of November. At Prappach the parasitism rate started at $17 \%$, peaked at $27 \% 8$ days later and declined slowly to $6 \%$. Parasitism at Rauchberg started at $17 \%$, climbed in 22 days to $72 \%$ and then stayed at around $60 \%$ until beginning of November. After the beginning of November the number of newly deposited egg clutches was very low, thus there was a high variation in parasitism between sample dates. However, on combining the results for all three sites, parasitism stayed at around 30 percent until the end of the beetle's oviposi- 


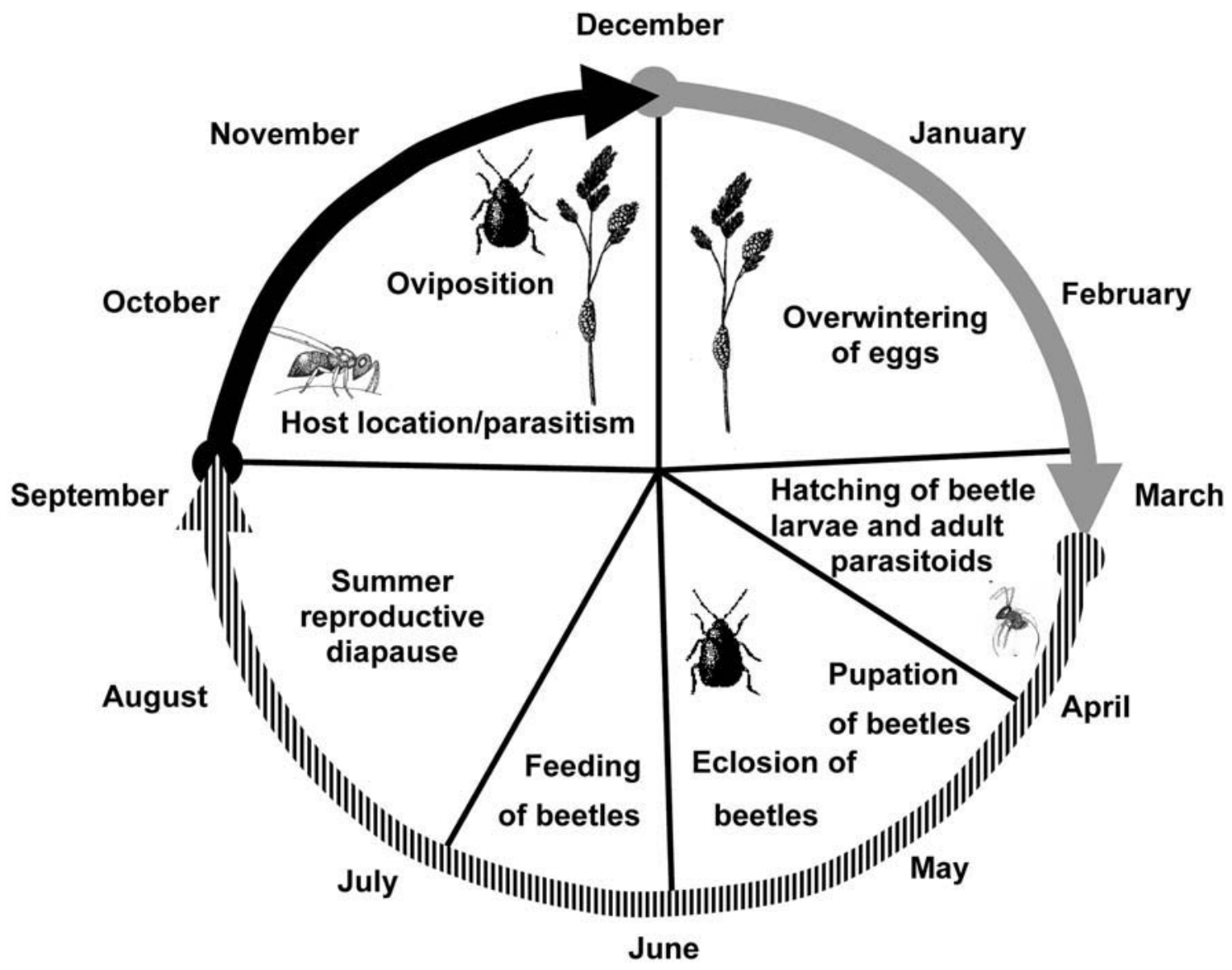

Fig. 1. Phenology of Galeruca tanaceti and Oomyzus galerucivorus. Hatched arrow: Adult parasitoids present but not host eggs. Black arrow: Beetle oviposition and host location by parasitoids. Grey arrow: Overwintering eggs and development of beetle and parasitoid larvae inside eggs.

tion period in the middle of December. Thus, parasitism started after a lag of about 10 days and fluctuated around a site-specific level until the end of the season.

\section{Temperature effects on oviposition and parasitism}

At all three sites the mean daytime temperature was very similar (Fig. 2C). In September it fluctuated between 10 and $13^{\circ} \mathrm{C}$, at the beginning of October it peaked at $16^{\circ} \mathrm{C}$ and decreased gradually to $0^{\circ} \mathrm{C}$ in the middle of November. It then stayed between $0^{\circ} \mathrm{C}$ and $4^{\circ} \mathrm{C}$ until the end of oviposition, one month later.

There was a highly significant positive correlation between the number of newly deposited egg clutches of $G$. tanaceti and temperature at all three sites (Schafhof: $\mathrm{r}_{\mathrm{s}}$ $=0.80, \mathrm{p}<0.001, \mathrm{n}=17$; Prappach: $\mathrm{r}_{\mathrm{s}}=0.91, \mathrm{p}<0.001$, $\mathrm{n}=17$; Rauchberg: $\left.\mathrm{r}_{\mathrm{s}}=0.71, \mathrm{p}<0.002, \mathrm{n}=17\right)$. The combined coefficients of the three correlations analysed in a meta-analysis were also highly significant $(Z=5.64$, $\mathrm{p}<0.001)$.

The parasitism rate was not correlated with temperature when the sites were analysed separately (Schafhof: $r_{\mathrm{s}}=$ $0.14, \mathrm{p}=0.634, \mathrm{n}=14$; Prappach: $\mathrm{r}_{\mathrm{s}}=-0.418, \mathrm{p}=0.177$, $\mathrm{n}=12$; Rauchberg: $\mathrm{r}_{\mathrm{s}}=0.423, \mathrm{p}=0.149, \mathrm{n}=13$ ) or when the coefficients were combined $(Z=0.38$, n.s.).

\section{Host-parasitoid interaction in time}

If enemy free space in time for the beetle eggs exists, the expectation is a significant negative relationship between rate of parasitism and number of egg clutches of the beetle over the season, since beetle oviposition should take place preferentially when parasitism pressure is low. Regressions calculated for the residuals of rate of parasitism (percentage of parasitised egg clutches) and the residuals of egg clutch numbers (corrected for temperature effects) were not significant for any of the three sites (Schafhof: $\mathrm{R}_{\text {corrected }}=0.110, \mathrm{~F}=2.602, \mathrm{p}=0.133, \mathrm{~B}=$ 0.422; Rauchberg: $\mathrm{R}_{\text {corrected }}^{2}=0.232, \mathrm{~F}=4.618, \mathrm{p}=0.055$, $\mathrm{B}=0.617$; Prappach: $\mathrm{R}_{\text {corrected }}^{2}=0.041, \mathrm{~F}=1.555, \mathrm{p}=$ $0.236, \mathrm{~B}=0.339$ ) and regression coefficients $(\mathrm{B})$ were positive for all three sites.

\section{DISCUSSION}

Insect hosts utilizing the full potential of their fundamental ecological niche and being active at places or times when abiotic or biotic conditions are unfavourable might thus be enabled to escape parasitism (e.g. Stamp, 2001; Tammaru et al., 2001). Although they are likely to have a reduced reproductive output due to the disadvantageous conditions (e.g. less or low quality food, low temperatures), the net reproductive gain due to reduced parasitism should be higher (Berdegue et al., 1996). 

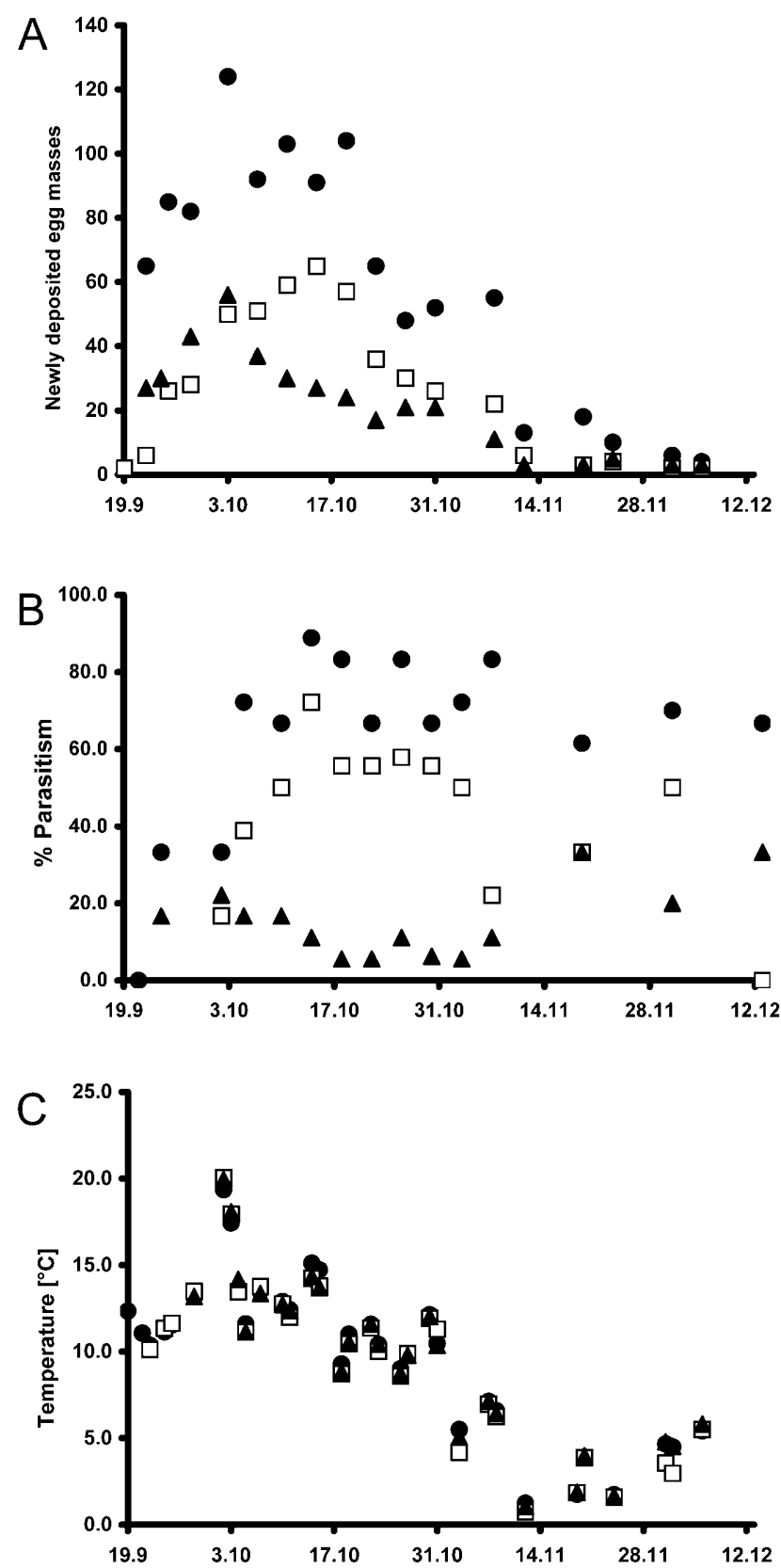

Fig. 2. (A) Number of newly deposited egg clutches of Galeruca tanaceti recorded from 19.09. to 12.12., (B) percentage parasitism of the egg clutches by the parasitoid Oomyzus galerucivorus, $(\mathrm{C})$ average temperature at all three sites in autumn. The sites were Schafhof (circle), Prappach (triangle) and Rauchberg (square). Mean values and standard deviations are given.

Despite the positive dependency of oviposition on temperature, $G$. tanaceti females are capable of producing and depositing eggs at very low temperatures even in the middle of December. While the population-wide tansy leaf beetle oviposition rates quickly increased to a maximum and then constantly declined until the end of the reproductive period, the parasitism rate rose after a lag at the beginning of the oviposition season to a more or less constant level. At all three sites tansy leaf beetle egg clutches laid at the end of the season (November December) had a similar probability of parasitism as egg clutches oviposited earlier. Instead of the expected negative relationship between the two variables "egg clutch number" and "rate of parasitism" over time if there is enemy free space at the end of the year, none of the regression coefficients for the three sites were significant and they were all positive. Thus, oviposition late in a year and at low temperatures does not enable the beetle to escape from its parasitoid. It was suspected that parasitism would cease earlier than beetle oviposition, due to a stronger negative effect of low temperatures on the parasitoid due to its small body size and associated negative effects on thermoregulation (Willmer, 1985). Campbell et al. (1974) found that temperature requirements of the parasitoids (and hyperparasitoids) associated with aphids are higher than those of their hosts. In contrast the egg parasitoid $O$. galerucivorus remained active and successfully parasitised its host even very late in the year. In other host-parasitoid systems a temporal escape from parasitism at the end of the season occurs. The parasitism of lepidopteran cocoons by a chrysidid wasp was lower at the end of the flight period (Yamada, 1987).

Oviposition activity of $G$. tanaceti decreased at all three sites over the oviposition period. One explanation for this could be the death of females and decrease in individual oviposition rates at the end of the season. Another possibility is that due to decreasing temperatures, egg development took longer, probably due to decreased food intake and diminished energy recovery from the food. The latter hypothesis is supported by a significant positive correlation between oviposition activity and temperature at all three sites. Another indication of the importance of temperature is that in autumn and winter tansy leaf beetles can be observed on the tops of dead grasses basking in the sun (T. Meiners, B. Randlkofer, pers. observ.). Female beetles might thus occupy warmer oviposition sites and use radiative heating to increase their body temperature and enhance the development of their eggs, which are oviposited as high as possible in the vegetation (Obermaier et al., 2006). Although low temperatures generally restrict locomotion in terrestrial arthropods, several Antarctic species gain a significant advantage by being able to forage, feed and hunt at temperatures near $0^{\circ} \mathrm{C}$. Mobility is often extended to below $0^{\circ} \mathrm{C}$ in mites and Collembola (Block, 1981; Schenker \& Block, 1986) and a number of polar insects are able to move at $-4^{\circ} \mathrm{C}$ (Lee \& Baust, 1987). The egg parasitoid, O. galerucivorus, was also able to parasitise the eggs of its host at low mean temperatures $\left(0-6^{\circ} \mathrm{C}\right)$ on cold November days in the field. In a previous study it was revealed that parasitism of $G$. tanaceti eggs by $O$. galerucivorus was higher at places more exposed to the sun (Meiners \& Obermaier, 2004). The choice of favourable microhabitats is of great importance for terrestrial arthropods living in low temperature environments (Danks, 1991; Sømme \& Block, 1991). Many species that are active on the surface of snow in winter raise their body temperatures by basking in the sun (Danks, 1991), as might G. tanaceti (see above) and its parasitoid $O$. galerucivorus. Low temperatures might not only influence the ability of parasitoids to move, but also 
the availability and relevance of chemical signals used in host location (Meiners et al., 1997).

\section{CONCLUSIONS}

Our results revealed that the females of the egg parasitoid $O$. galerucivorus are capable of parasitising host eggs even at the end of a season when mean temperatures are around freezing. Thus tansy leaf beetles do not gain temporal enemy-free space against egg parasitism by ovipositing late in the season. There might be other explanations for late season oviposition in G. tanaceti. The eggs might not survive the long period until winter. Although the eggs are well protected during overwintering by a special hard secretion (Scherf, 1966; Messner, 1983), a long hot season before winter may be hazardous with eggs desiccating due to their large surface area relative to size (Masaki, 1978). Furthermore activity in autumn and winter rather than summer is supposed to offer greater protection from predators or generalist parasitoids, since the overall predation pressure is supposed to be higher in summer (e.g., Tammaru et al., 2001). By laying their eggs late in the season, beetles might be able to select oviposition substrates (e.g. grass stems) that are stable and offer better protection against winter-mortality (Obermaier et al., 2006). Further studies on the walking, feeding and oviposition activity, and the chemical orientation of the host and the parasitoid at low temperatures, are needed to fully understand the late season interactions between $G$. tanaceti and its specialised egg parasitoid.

ACKNOWLEDGEMENTS. We thank H.-J. Poethke for encouraging and hosting this study at the ecological field station. T. Hovestadt contributed helpful comments on statistics. T. Tammaru and two anonymous reviewers provided helpful comments on an earlier version of the manuscript. E. Obermaier also thanks the bureau of women's affairs of the University of Würzburg and the BMBF (MOSAIC-project, code 01LN0007) for financial support. The authors thank the council of lower Franconia for permission to work in the nature reserve.

\section{REFERENCES}

Berdegue M., Trumble J.T., Hare J.D. \& Redak R.A. 1996: Is it enemy-free space? The evidence for terrestrial insects and freshwater arthropods. Ecol. Entomol. 21: 203-217.

Block W. 1981: Terrestrial arthropods at low temperatures. Cryobiology 18: 436-444.

Campbell A., Frazer B.D., Gilbert N., Gutierrez A.P. \& MACKAUER M. 1974: Temperature requirements of some aphids and their parasites. J. Appl. Ecol. 11: 431-438.

Clancy K.M. \& Price P.W. 1987: Temporal variation in threetrophic-level interactions among willows, sawflies and parasites. Ecology 67: 1601-1607.

DANKS H.V. 1991: Winter habitats and ecological adaptations for winter survival. In Lee Jr. R.L. \& Denlinger D.L. (eds): Insects at Low Temperatures. Chapman \& Hall, New York, pp. 231-259.

EISEND M. 2004: Metaanalyse - Einführung und kritische Diskussion. Diskussionsbeiträge des Fachbereichs Wirtschaftswissenschaft der Freien Universität Berlin, Nr. 2004/8. Betriebswirtschaftliche Reihe, Berlin, pp. 1-44.

Hopkins G.W. \& Dixon A.F.G. 1997: Enemy-free space and the feeding niche of an aphid. Ecol. Entomol. 22: 271-274.
Jeffreys M.J. \& Lawton J.H. 1984: Enemy free space and the structure of ecological communities. Biol. J. Linn. Soc. 23: 269-286.

Lee R.E. \& Baust J.G. 1987: Cold hardiness in the Antarctic tick, Ixodes uriae. Physiol. Zool. 60: 499-506.

MASAKI S. 1978: Seasonal and latitudinal adaptations in the life cycles of crickets. In Dingle H. (ed.): Evolution of Insect Migration and Diapause. Springer, New York, pp. 72-100.

Meiners T. \& Obermaier E. 2004: Hide and seek on two spatial scales-vegetation structure affects herbivore oviposition and egg parasitism. Basic Appl. Ecol. 5: 87-94.

Meiners T., KöpF A., Stein C. \& Hilker M. 1997: Chemical signals mediating interactions between Galeruca tanaceti L. (Coleoptera, Chrysomelidae) and its egg parasitoid Oomyzus galerucivorus (Hedqvits) (Hymenoptera, Eulophidae). $J$. Insect Behav. 10: 523-539.

MESSNER B. 1983: DOPA-oxidase-gehärtete Sekrete schützen das Eigelege von Galeruca tanaceti L. (Coleoptera, Chrysomelidae). Entomol. Nachr. Berichte 27: 221-224.

OBERMAIER E. \& ZwÖLFER H. 1999: Plant quality or quantity? Host exploitation strategies in three Chrysomelidae species associated with Asteraceae host plants. Entomol. Exp. Appl. 92: $165-177$.

Obermaier E., Heisswolf A., Randlkofer B. \& Meiners T. 2006: Enemies in low places - Insects avoid winter mortality and egg parasitism by modulating oviposition height. Bull. Entomol. Res. (in press).

Prevett P.F. 1953: Notes on the feeding habits and life-history of Galeruca tanaceti L. (Col., Chrysomelidae). Entomol. Month. Magaz. 89: 292-293.

Price P.W., Bouton C.E., Gross P., McPheron B.A., Thompson J.N. \& WeIs A.E. 1980: Interactions among three trophic levels: influence of plants on interactions between insect herbivores and natural enemies. Annu. Rev. Ecol. Syst. 11: 41-65.

RAUSHER M.D. 1979: Larval habitat suitability and oviposition preference in three related butterflies. Ecology 60: 503-511.

SCHENKER R. \& Block W. 1986: Micro-arthropod activity in three contrasting terrestrial habitats on Signy island, Maritime Antarctic. Brit. Antarct. Surv. Bull. 71: 31-41.

SCHERF H. 1966: Beobachtungen an Ei und Gelege von Galeruca tanaceti L. (Coleoptera, Chrysomelidae). Biol. Zentralbl. 85: $7-17$.

SIEW Y.C. 1966: Some physiological aspects of adult reproductive diapause in Galeruca tanaceti (L.) (Coleoptera: Chrysomelidae). Trans. R. Entomol. Soc. Lond. 118: 359-374.

SinACORI A. \& Mineo G. 1993: Nota preliminare su Galeruca spp. (Coleoptera: Chrysomelidae) delle Madonie. Frust. Entomol. 16: 97-110.

SoKal R.R. \& RohlF F.J. 1994: Biometry. 3rd ed. W.H. Freeman, New York, 887 pp.

Sømme L. \& Block W. 1991: Adaptations to Alpine and polar environments in insects and other terrestrial arthropods. In Lee Jr. R.L. \& Denlinger D.L. (eds.): Insects at Low Temperatures. Chapman \& Hall, New York, pp. 318-359.

Stamp N. 2001: Enemy-free space via host plant chemistry and dispersion: assessing the influence of tri-trophic interactions. Oecologia 128: 153-163.

StAmp N. \& Bowers M. 1988: Direct and indirect effects of predatory wasps (Polistes sp.: Vespidae) on gregarious caterpillars (Hemileuca lucina: Saturniidae). Oecologia 75: 619-624.

Strohm E., Laurien-Kehnen C. \& Bordon S. 2001: Escape from parasitism: spatial and temporal strategies of a sphecid wasp against a specialised cuckoo wasp. Oecologia 129: 50-57. 
Tammaru T., TanhuanpäÄ M., Ruohomäki K. \& Vanatoa A. 2001: Autumnal moth - why autumnal? Ecol. Entomol. 26: 646-654.

WILLMER P. 1985: Size effects and hygrothermal balance and foraging patterns of a sphecid wasp, Cerceris arenaria. Ecol. Entomol. 10: 469-479.
YAMADA Y. 1987: Factors determining the rate of parasitism by a parasitoid with a low fecundity, Chrysis shanghaiensis (Hymenoptera: Chrysididae). J. Animal Ecol. 56: 1029-1042.

Received March 6, 2006; revised and accepted June 2, 2006 